\title{
Adjusting the weaning age of calves fed by automated feeders according to individual intakes of solid feed
}

\author{
A. M. de Passillé ${ }^{1}$ and J. Rushen \\ Pacific Agri-Food Research Centre, Agriculture and Agri-Food Canada, Agassiz, BC V0M 1A0, Canada
}

\begin{abstract}
When weaned at the ages typical of commercial dairy production, dairy calves usually show reduced growth rates, lowered energy intake, and increased behavioral signs of hunger, reflecting their difficulty in switching from a milk diet to solid feed. However, large differences exist between calves in their ability to adapt to solid feed, and automated feeders allow the age of weaning to be adjusted to an individual calf's intake of solid feed. We examined the effects of weaning according to solid feed intake on age at weaning, feed intake, and behavioral signs of hunger. In a $2 \times 2$ factorial design, 60 female Holstein calves in groups of 8 and fed milk, grain starter, and hay from automated feeders began to be weaned when their voluntary intake of grain starter was either $400 \mathrm{~g} / \mathrm{d}$ (high start) or $200 \mathrm{~g} / \mathrm{d}$ (low start), with weaning completed when their voluntary intakes of starter were either $1,600 \mathrm{~g} / \mathrm{d}$ (high end) or $800 \mathrm{~g} / \mathrm{d}$ (low end). Digestible energy intakes were calculated from milk, starter and hay intakes, corrected for body weights, calves were weighed, and the frequency of visits to the milk feeders were measured each day. The main effects and interactions between treatments were tested with ANOVA. Large differences were observed between calves in the age at which weaning was complete, with weaning completed earlier for low-end calves compared with high-end calves. No treatment effects (either of start amount or end amount) on intakes of milk, starter, or hay or on weight gains occurred. However, the calves that began weaning earlier had longer durations of weaning, greater growth rates from d 20 to 87, and were heavier on d 87, and had lower milk intakes, higher starter intakes, higher hay intakes, and a greater digestible energy intake, but showed more unrewarded visits to the milk feeder. Adjusting the age at which individual calves are weaned off milk according to their ability to eat solid feed can reduce the age at which weaning occurs while reducing the negative effects of weaning on energy intake and weight gain, although
\end{abstract}

Received March 9, 2012.

Accepted May 7, 2012.

${ }^{1}$ Corresponding author: Annemarie.Depassille@agr.gc.ca the increased visits to the milk feeder during weaning suggest that calves remain motivated to drink milk.

Key words: calf, weaning, energy intake, automated feeding

\section{INTRODUCTION}

Research is accumulating showing the advantages of feeding dairy calves more milk than has been the tradition (Jasper and Weary, 2002; Khan et al., 2011a; Soberon et al., 2012). The positive effects of this on first-lactation milk yield appear to depend on the daily weight gain (WG) of the calves (Soberon et al., 2012). However, one problem with feeding calves large amounts of milk is that their intakes of solid feed can be reduced, leading to weight loss at weaning, thus losing the weight advantage of feeding more milk (Sweeney et al., 2010; de Passillé et al., 2011). This weight loss can be reduced by weaning at a later age (de Passillé et al., 2011), which does increase the amount of milk or milk replacer required. However, a large difference exists between calves in how much weight they lose or gain while being weaned (de Passillé et al., 2011), and calves vary in the age at which they can be weaned onto solid feed (Roth et al., 2009). One advantage with automatic feeders for calves is that they allow milk allowance to be adjusted according to each individual calf's daily intakes of solid feed, which can result in earlier weaning for some calves without any reductions in health, WG, or rumen development (Roth et al., 2009). Despite its promise, this method of weaning calves has not received much attention from researchers and little is known about the optimum targets of intake of solid food that can be used to adjust the weaning period. Our objective was to examine the effects of different target levels of starter intake that could be used to begin and to end weaning on weaning ages, WG, feed intakes, and behavioral signs of hunger of calves fed large amounts of milk from automated feeders.

\section{MATERIALS AND METHODS}

This study was conducted at the University of British Columbia (UBC) Dairy Education and Research Cen- 
ter in Agassiz, BC, Canada. The Institutional Animal Care Committee (monitored by the Canadian Council for Animal Care) approved all procedures described in this study.

\section{Housing and Management}

Sixty female Holstein calves were removed from their mothers and moved into individual sawdust-bedded pens $(1.22 \times 2.44 \mathrm{~m})$ within $24 \mathrm{~h}$ of birth, where they were bottle-fed whole milk twice per day to ad libitum intake and had ad libitum access to water in buckets. At 4 to $6 \mathrm{~d}$ of age $($ mean $=5.4 \mathrm{~d})$, the calves were moved into $4.87 \times 7.31-\mathrm{m}$ wood shavings-bedded pens with a partially slatted floor (described in Sweeney et al., 2010). Fresh bedding of wood shavings was added to each pen once per week. We used 7 groups of 8 calves and 1 group of 4 calves, with a maximum age range of $21 \mathrm{~d}$ within the pens. Calves were fed milk and starter from automated feeders, with both feeders controlled by a single computer (CF 1000 CS Combi; DeLaval Inc., Tumba, Sweden). Calves were allowed $12 \mathrm{~L}$ of pasteurized milk/d (herd averages of $3.97 \%$ fat, $4.10 \%$ protein, and $3.30 \%$ lactose from bulk tank samples) at $40^{\circ} \mathrm{C}$ and had ad libitum access to a textured calf starter $(\mathrm{CP}=17.9 \%$ on a $\mathrm{DM}$ basis, with the main ingredients being $16 \%$ wheat, $14 \%$ barley, $13 \%$ canola meal, $13 \%$ oats, $10 \%$ soya, $10 \%$ corn, and $4 \%$ molasses; Unifeed Ltd., Chilliwack, BC, Canada). Grass hay $(\mathrm{DM}=90.8 \%, \mathrm{CP}=15.1 \%, \mathrm{NDF}=51.1 \%$, and $\mathrm{ADF}=33.6 \%$ ) and water were available ad libitum from automated feeders that weighed the intake of each calf at each meal (RIC; Insentec B. V., Marknesse, the Netherlands). Weigh scales (Western Scale Inc., Port Coquitlam, BC, Canada) were placed in the feeders and weighed the calves during every visit.

\section{Experimental Treatments}

On being moved into group pens, the calves were assigned to 1 of 4 different treatments, balancing for birth weight and age. The treatments involved different target weights for starter intake to begin weaning off milk and to complete the weaning. Two target weights for beginning weaning were used. For low-start calves, the weaning began when the calves had consumed an average of $200 \mathrm{~g}$ of starter/d during the preceding $3 \mathrm{~d}$, whereas for high-start calves, weaning began when the calves had consumed an average of $400 \mathrm{~g}$ of starter/d during the preceding $3 \mathrm{~d}$. For low-end calves, the weaning was completed (i.e., milk allowance reduced to zero) when the calves had consumed an average of $800 \mathrm{~g}$ of starter/d during the preceding $3 \mathrm{~d}$, whereas for high- end calves, the weaning was completed when the calves had consumed an average of 1,600 $\mathrm{g}$ of starter/d during the preceding $3 \mathrm{~d}$. The treatments were applied in a 2 $\times 2$ factorial design. Once a calf began to be weaned, milk allowance was progressively reduced according to when the calves' intake of starter reached certain set intermediate targets. Intermediate targets for starter intakes were calculated so that the calves would progress from the start target to the end target in 4 steps. For example, low-start, low-end calves had targets of $200,400,600$, and $800 \mathrm{~g} / \mathrm{d}$. Once the calf had reached the target over the 3 preceding days, the milk allowance was reduced by $3 \mathrm{~L} / \mathrm{d}$. One pen contained 1 calf from each treatment, whereas the remaining pens contained 2 calves from each treatment. In pens with 8 calves, the first 4 calves added to the pen contained 1 calf from each treatment, as did the second 4 calves added to the pens.

Because of the physical design of our feeder system, calves can have difficulty accessing the feeders when they reach a certain size. To prevent this, we had to place a limit on the age at which calves could continue drinking milk. If the calves had not finished weaning by $74 \mathrm{~d}$ of age, they were automatically weaned by progressively reducing their milk allowance over a 7 -d period. We refer to these as animals as force-weaned calves. Because of technical issues associated with the computer, all reported ages are $\pm 2 \mathrm{~d}$, although we used the real age of the calves in doing the analyses.

\section{Data Analysis}

The quantities of milk, starter, hay, and water consumed by each calf at each meal were automatically recorded and converted to daily intakes. We estimated daily digestible energy (DE) intake for each individual calf based on the analysis of samples of calf starter and hay (Bodycote Testing Group Inc., Lethbridge, $\mathrm{AB}$, Canada). The mean DE content that was calculated from the analyzed chemical constituents was 3.48 $\mathrm{Mcal} / \mathrm{kg}$ for starter and $2.40 \mathrm{Mcal} / \mathrm{kg}$ for hay. Milk was estimated to contain $5.59 \mathrm{Mcal}$ of DE/kg (NRC, 2001).

We recorded for each calf the age at which the milk allowance was first reduced, the age at which the calf was fully weaned (no milk allowance), and the duration of weaning. Mean values for daily intake of milk, starter, hay, water and DE were calculated for each day. The mean daily number of visits (both rewarded and unrewarded) by each calf to the milk feeder was calculated from data from the milk feeders. Body weights were calculated each day based on the mean of all BW measurements from the feeders for that day. Weight gains over the whole period were calculated both as ac- 
tual WG and WG as a percentage of BW on d 20. The analysis was done in 2 time periods. First, we examined the whole period when weaning was occurring from $d$ 20 (the day before the first calf began to be weaned) to d 87 (1 wk after the last calf had been fully weaned). Second, we examined the period of actual weaning for each individual calf, beginning on the first day that milk allowance was reduced to the last day that the calf received some milk. This period varied from calf to calf.

The data for many variables were normally distributed, and so we used parametric tests. In some cases, however, the data were not normally distributed (e.g., for the frequency of visits to the milk feeder, for the age at the end of weaning, and the duration of weaning) and transformations were not successful in producing a normal distribution. In such cases, we also used nonparametric tests. However, as the parametric and nonparametric tests produced the same patterns of significance, we report the results of only the former.

During the overall period from d 20 to 87, we used a $2 \times 2$ ANOVA, with the start target and the end target as main factors and the interaction between them; the age at which weaning began and ended; the duration of weaning; BW on d 20 and 87; daily WG; intakes of milk, starter, and hay (both total and expressed as percentage of BW on d 20); and mean daily frequency of visits to the milk feeder as dependent variables. We also calculated Pearson correlations between these variables. To account for growth differences that were present before the weaning began, we also calculated daily WG from d 7 to 20 and correlated these with later intakes and weaning variables. These analyses were done using all calves, including the force-weaned calves. During the weaning period for each calf, we did the same $2 \times 2$ analysis for daily intakes of milk, starter, hay and DE, daily WG (all expressed as a percentage of initial BW), and daily frequency of visits to the milk feeder. These analyses were done by excluding the force-weaned calves.

\section{RESULTS}

Eleven (20\%) of the calves did not reach the targets to begin the weaning procedure and so were forceweaned beginning at $74 \mathrm{~d}$. Eight of these calves were in the high-start group (low end $=5$ calves; high end $=$ 3 calves) and only 3 in the low-start group (low end $=$ 2 calves; high end $=1$ calf). These force-weaned calves had lower BW on d $20(53.4 \pm 2.4$ vs. $59.6 \pm 1.2 \mathrm{~kg}$; $P=0.02)$ and $\mathrm{d} 87(95.2 \pm 3.7$ vs. $130.9 \pm 1.9 \mathrm{~kg} ; P$ $<0.001)$ than the calves that were successfully weaned before d 74 .

Calves differed greatly in the ages at which they reached the target intakes of starter, and the weaning process began, which varied from 22 to $74 \mathrm{~d}$ of age. A nonsignificant trend was observed for low-start calves to start weaning earlier than high-start calves (Table 1 ). The age at which weaning ended was affected by the ending amount, with low-end calves being fully weaned at an earlier age (Table 1). However, the age at which weaning was completed was highly variable between calves, with considerable overlap between the treatment groups (Figure 1). The duration of weaning was also highly variable, ranging from 4 to $38 \mathrm{~d}$, and was affected by both the starting amount and the end amount, with longer durations of weaning occurring for low-start calves and high-end calves (Table 1). The duration of weaning for the treatment group high startlow end was particularly short (Table 1), with 3 calves being weaned in $4 \mathrm{~d}$ and only 2 calves taking $10 \mathrm{~d}$ or longer. No interaction existed between starting amount and ending amount on any measure relating to the age or duration of weaning $(P>0.10)$. A negative correlation existed between the age at the start of weaning and the duration of weaning $(\mathrm{r}=-0.67 ; P<0.0001)$, with calves that began weaning earlier having a longer duration of weaning.

Over the whole period from d 20 of age to d 87 of age, no effects were observed of starting amount or ending

Table 1. Least squares means $( \pm \mathrm{SE})$ of the age at which weaning started and ended and the duration of weaning for calves ${ }^{1}$ with either a low target amount of starter to start weaning $(200 \mathrm{~g} / \mathrm{d})$ or a high target amount of starter to start weaning $(400 \mathrm{~g} / \mathrm{d})$ and a low target amount of starter to end weaning $(800 \mathrm{~g} / \mathrm{d})$ or a high target amount of starter to end weaning $(1,600 \mathrm{~g} / \mathrm{d})$

\begin{tabular}{|c|c|c|c|c|c|c|c|}
\hline \multirow[b]{2}{*}{ Variable } & \multicolumn{4}{|c|}{ Treatment $^{2}$} & \multicolumn{3}{|c|}{$P$-value ${ }^{3}$} \\
\hline & LL & $\mathrm{LH}$ & HL & $\mathrm{HH}$ & Start & End & $\mathrm{S} \times \mathrm{E}^{4}$ \\
\hline Age weaning ends (d) & $61.1 \pm 3.2$ & $64.4 \pm 2.7$ & $58.1 \pm 3.2$ & $69.0 \pm 3.1$ & NS & $<0.0001$ & NS \\
\hline Duration of weaning (d) & $10.5 \pm 2.3$ & $23.1 \pm 1.9$ & $7.5 \pm 2.3$ & $13.6 \pm 2.1$ & 0.006 & $<0.0001$ & NS \\
\hline
\end{tabular}

${ }^{1}$ Force-weaned calves were removed for this analysis.

${ }^{2} \mathrm{LL}=$ low start, low end; $\mathrm{LH}=$ low start, high end; HL = high start, low end; HH = high start, high end.

${ }^{3}$ Probabilities shown are from the general linear model analysis of the effects of starting amount, ending amount, and interaction.

${ }^{4} \mathrm{~S} \times \mathrm{E}=$ interaction between starting amount and ending amount. 


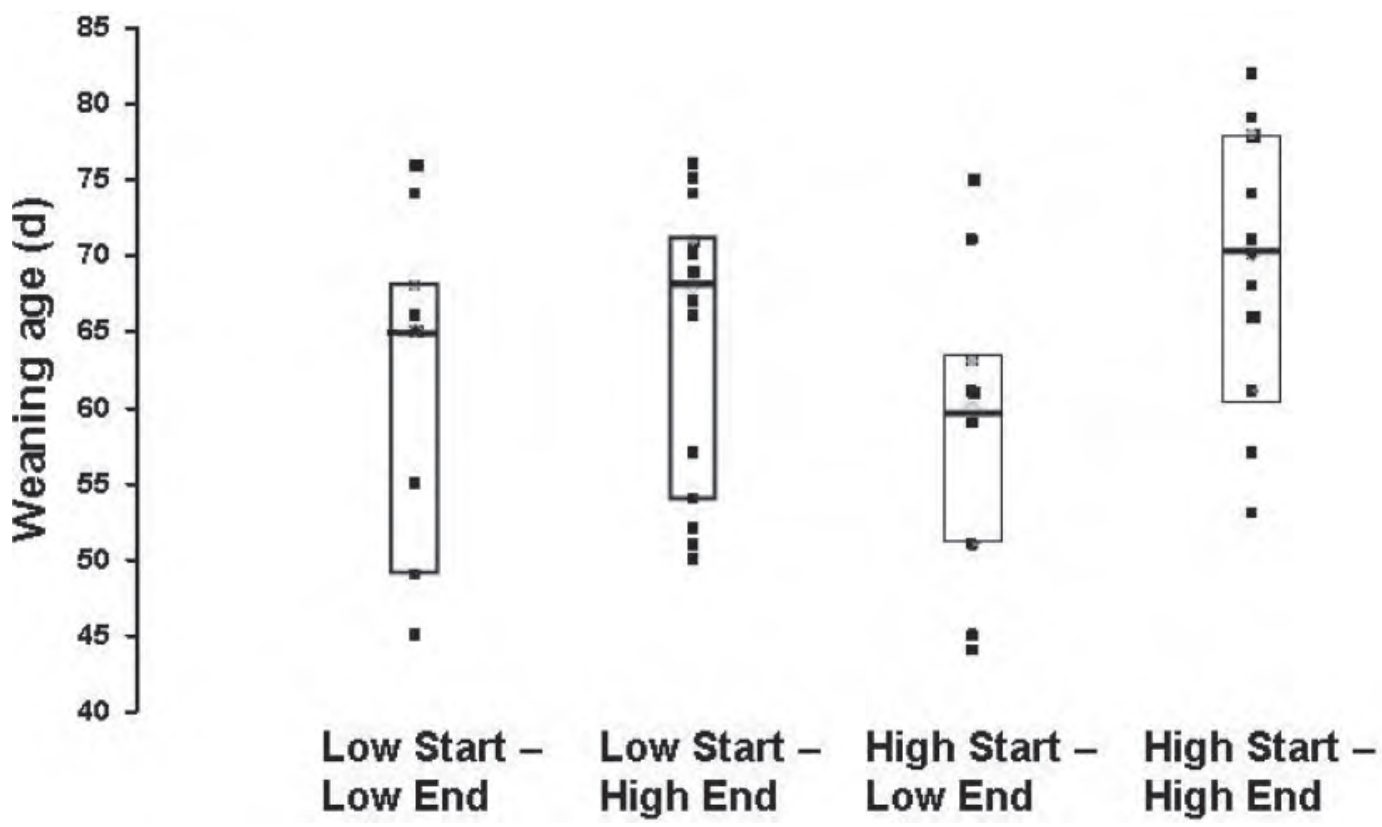

Figure 1. Age at which weaning was completed (i.e., the first day that the calf received no milk) for calves whose weaning began when they had consumed $200 \mathrm{~g}$ of starter/d (low start) or $400 \mathrm{~g}$ of starter/d (high start) and whose weaning was completed when they had consumed either $800 \mathrm{~g}$ of starter/d (low end) or 1,600 g of starter/d (high end). Each point represents an individual calf; the upper and lower boundaries of the box represent the 75 th and 25 th percentiles, respectively, and the line in the middle represents the median.

amount or interaction between these on BW; WG; or overall intakes of milk, starter, or hay $(P>0.10)$ (Table 2 ). The amount of milk consumed was negatively correlated with starter intake $(\mathrm{r}=-0.85 ; P<0.0001)$ and hay intake $(\mathrm{r}=-0.37 ; P=0.004)$ and a positive correlation was found between starter intake and hay intake $(\mathrm{r}=0.30 ; P=0.02)$.

The frequency of visits to the milk feeder was higher for calves on the low-start treatment than for calves on the high-start treatment $(P=0.004$; Table 2$)$. The frequency of visits to the milk feeder was negatively correlated with milk intake $(\mathrm{r}=-0.40 ; P=0.002)$ but positively correlated with overall DE intake $(\mathrm{r}=0.56$; $P<0.0001)$.
Several correlations were observed between the ages at which weaning occurred and feed intakes, BW, and WG (Table 3). Neither the ages at which weaning started or ended nor the duration of weaning were correlated with BW on d 20 (the last day before the first calf began to be weaned) or the WG from d 7 to 20. However, WG from d 20 to 87 and $\mathrm{BW}$ on d 87 were negatively correlated with the age at which weaning began and ended and positively correlated with the duration of weaning (Table 3). Calves that began weaning earlier also had lower milk intakes, higher starter intakes, higher hay intakes, and a greater DE intake, but showed more visits to the milk feeder (Table 3).

Table 2. Least squares means $( \pm \mathrm{SE})$ of BW on d 20 and 87 ; daily weight gain (WG); total intakes of milk, starter, and hay between d 20 and 87; and daily frequency of visits to the milk feeder between d 20 and 87 for calves on high or low target starter amounts to start and end weaning

\begin{tabular}{|c|c|c|c|c|}
\hline \multirow[b]{2}{*}{ Variable } & \multicolumn{4}{|c|}{ Treatment $^{1}$} \\
\hline & LL & $\mathrm{LH}$ & HL & $\mathrm{HH}$ \\
\hline BW on d $87(\mathrm{~kg})$ & $123.6 \pm 5.2$ & $129.7 \pm 4.8$ & $121.6 \pm 4.8$ & $119.1 \pm 4.8$ \\
\hline Daily WG (kg/d) & $0.98 \pm 0.06$ & $1.03 \pm 0.06$ & $0.92 \pm 0.06$ & $0.91 \pm 0.06$ \\
\hline Daily WG ( $\%$ of BW on $\mathrm{d} 20)$ & $1.71 \pm 0.11$ & $1.74 \pm 0.11$ & $1.55 \pm 0.11$ & $1.61 \pm 0.11$ \\
\hline Milk (L) & $393.8 \pm 33.6$ & $367.6 \pm 31.3$ & $384.6 \pm 31.3$ & $413.8 \pm 31.3$ \\
\hline Daily visits & $5.84 \pm 0.72$ & $6.81 \pm 0.67$ & $5.04 \pm 0.67$ & $3.49 \pm 0.66$ \\
\hline
\end{tabular}

${ }^{1} \mathrm{LL}=$ low start, low end; LH = low start, high end; HL = high start, low end; HH = high start, high end. 
Table 3. Correlations (across all calves) between the ages at which weaning started and ended and the duration of weaning with BW on d 20 and 87; daily weight gain (WG); total intakes of milk, starter, hay, and estimated digestible energy (DE) between d 20 and 87; and daily frequency of visits to the milk feeder between d 20 and 87

\begin{tabular}{|c|c|c|c|c|c|c|}
\hline Variable & \multicolumn{2}{|c|}{ Age at start } & \multicolumn{2}{|c|}{ Age at end } & \multicolumn{2}{|c|}{ Duration } \\
\hline BW on d 20 & -0.09 & NS & -0.16 & NS & -0.05 & NS \\
\hline WG d 7 to 20 ( $\%$ of $\mathrm{BW})$ & 0.20 & NS & 0.12 & NS & -0.20 & NS \\
\hline WG d 20 to 87 ( $\%$ of $B W)$ & -0.61 & $<0.0001$ & -0.50 & $<0.0001$ & 0.44 & 0.0005 \\
\hline Milk intake & 0.82 & $<0.0001$ & 0.84 & $<0.0001$ & -0.40 & 0.002 \\
\hline Total DE intake & -0.69 & $<0.0001$ & -0.72 & $<0.0001$ & 0.31 & 0.02 \\
\hline Daily visits & -0.51 & $<0.0001$ & -0.44 & $<0.0001$ & 0.36 & 0.006 \\
\hline
\end{tabular}

During the actual period of weaning for each calf, the high-end calves had higher intakes of milk than did low-end calves (Table $4 ; P=0.03$ ) and tended to have higher overall DE intakes (Table $4 ; P=0.10$ ). There were no differences in starter intake, hay intake, or frequency of visits to the milk feeder between high-end and low-end calves, and no effect of starting amount or interaction between starting amount and ending amount on any variable $(P>0.10)$. Milk intake was negatively correlated with starter intake $(\mathrm{r}=-0.42$; $P=0.004)$ but there were no correlations between hay intake and intakes of milk or starter $(P>0.10)$. The frequency of all visits to the milk feeder tended to be negatively correlated with milk intake $(\mathrm{r}=-0.25 ; P$ $=0.07)$ but was not correlated with $\mathrm{DE}$ intake $(P>$ $0.10)$. Weight gains during the period of actual weaning were greatest in the high-end calves compared with low-end calves (Table $4 ; P=0.007$ ). Only 1 calf lost weight $(-0.24 \mathrm{~g} / \mathrm{kg}$ of $\mathrm{BW})$ and this was a high-startlow-end calf.

\section{DISCUSSION}

Our results agree with those of Roth et al. (2009) in showing the advantages of adjusting weaning according to individual calves' abilities to eat solid feed. Large differences exist between calves in the ages that they can be weaned onto solid feed, and weaning calves according to individual starter intakes can reduce the age at weaning while reducing the negative effects of weaning on WG.

Little is known about the optimum targets for starter intake to use to begin and end weaning. We did not find strong effects of the particular target for starter intake used to begin the weaning process. Having a smaller target for beginning the weaning process increased the duration of weaning and resulted in more calves being successfully weaned within the time allowed, but did not have a strong effect on the age at which weaning began (although the trend was to reduce the age). The main disadvantage with the high-start treatment was that more calves were not weaned in the time allowed; these calves were smaller calves, suggesting that targets for starter intake should ideally be adjusted for the calf's size. When we examined both the whole period from $\mathrm{d}$ 20 to 87 , and the actual period when each calf was being weaned, the size of the target to begin weaning did not influence overall intakes of milk, starter, or hay, or the WG and final BW of the calves. This suggests that the lower target that we used $(200 \mathrm{~g} / \mathrm{d})$ is adequate to begin weaning, as long as the rate of weaning continues to be adjusted according to the intake of starter, which gives each calf a chance to progress through weaning at its own rate.

Having a smaller target for completing weaning had more effects. A smaller target to end weaning resulted in weaning being completed at an earlier age with a shorter duration of weaning. During the actual period when each calf was being weaned, a smaller end target resulted in a lower milk intake and a trend toward lower intakes of DE. Weight gains were also lower. This may reflect the fact that the low targets to end weaning resulted in some very short weaning periods (especially if combined with high targets to start weaning). This suggests that the higher end target $(1,600 \mathrm{~g} / \mathrm{d})$ is preferable. However, when we examined the whole period from d 20 to 87, the size of the target to end weaning had no effects on any intakes, BW, or WG. Thus, the size of the targets to start and end weaning did not have strong overall effects on the calves, except that one disadvantage with having too high a target to start weaning is that smaller calves will be weaned at a late age, whereas too low a target to end weaning results in some very short weaning periods.

Overall, the average age at which weaning was complete was about $67 \mathrm{~d}$, which is about $9 \mathrm{~d}$ younger than the age reported by Roth et al. (2009), who used target amounts of $700 \mathrm{~g}$ and $2 \mathrm{~kg}$. The most striking 
Table 4. Least squares means $( \pm \mathrm{SE})$ during the actual period of weaning (from the first day that milk allowance was reduced to the last day that each calf received milk) for average daily intakes of milk, starter, hay, and estimated digestible energy (DE); weight gain (WG); and frequency of visits to the milk feeder for calves ${ }^{1}$ on high or low target starter amounts to start and end weaning

\begin{tabular}{|c|c|c|c|c|c|c|}
\hline Variable & \multicolumn{4}{|c|}{ Treatment $^{2}$} & \multicolumn{2}{|c|}{$P$-value ${ }^{3}$} \\
\hline Milk (g/kg of BW) & $54.5 \pm 4.8$ & $67.6 \pm 4.1$ & $51.0 \pm 4.8$ & $58.6 \pm 4.6$ & NS & 0.03 \\
\hline Hay $(\mathrm{g} / \mathrm{kg}$ of $\mathrm{BW})$ & $2.7 \pm 0.5$ & $3.4 \pm 0.5$ & $3.6 \pm 0.5$ & $2.8 \pm 0.5$ & NS & NS \\
\hline $\mathrm{DE}(\mathrm{kCal} / \mathrm{kg}$ of BW) & $75.0 \pm 3.8$ & $83.6 \pm 3.2$ & $77.6 \pm 3.8$ & $80.9 \pm 3.6$ & NS & 0.10 \\
\hline $\mathrm{WG}(\%$ of $\mathrm{BW})$ & $0.87 \pm 0.17$ & $1.28 \pm 0.14$ & $0.90 \pm 0.17$ & $1.67 \pm 0.16$ & NS & 0.007 \\
\hline
\end{tabular}

${ }^{1}$ Force-weaned calves were removed for this analysis.

${ }^{2} \mathrm{LL}=$ low start, low end; $\mathrm{LH}=$ low start, high end; HL = high start, low end; HH = high start, high end.

${ }^{3}$ Probability values for the main effects of start amount and end amount. No interactions between start amount and end amount were significant $(P>0.10)$

result of our study, however, is the difference between calves in the ages at which they can be weaned when milk allowance is reduced according to their intakes of starter (found also by Roth et al., 2009). Despite the large amounts of milk they were drinking, some calves reached the target for starter intake and began to be weaned at a very early age (less than $30 \mathrm{~d}$ of age). Calves that began to be weaned earlier took longer to be fully weaned, drank less milk, but ate more starter and hay, and had better overall energy intakes and, consequently, had better WG. This did not reflect inherent differences between calves in growth rates, as the age that weaning began was not related to growth between $\mathrm{d} 7$ and 20 (i.e., the period before weaning began).

These results should not be interpreted as favoring earlier forced weaning, as previously we found that beginning weaning too early (around $20 \mathrm{~d}$ of age) can lead to reduced WG and increased cross-sucking (Sweeney et a., 2010). Rather, they show that we can profit by allowing individual calves to progress through weaning at their own rates, which is made possible by the use of automated feeders. Gradual weaning has been shown to be preferable than abrupt weaning (Nielsen et al., 2008; Sweeney et al., 2010) and these results suggest that calves differ in the duration of weaning that is optimal.

However, the calves that were weaned earlier did tend to visit the milk feeder more often, suggesting continued motivation to drink milk. Difficulties arise in interpreting the occurrence of such behaviors when calves are kept in groups. Social facilitation may result in a visit to the feeder by one calf stimulating other calves to visit. Alternatively, the fact that one calf is in the feeder may prevent others from entering. Thus, the results on the frequency of visits to the milk feeder must be interpreted with caution because of these social effects. Previous research has shown that calves receiving lower amounts of milk make more unrewarded visits to the milk feeder (Jensen, 2006; De Paula Vieira et al., 2008; Borderas et al., 2009) and that the frequency of visits increases with weaning (Nielsen et al., 2008; Sweeney et al., 2010; de Passillé et al., 2011). During weaning, the frequency of such visits is negatively correlated with energy intake (de Passillé et al., 2011), suggesting that this is a behavioral indicator of hunger in calves during the weaning process. These studies, however, examined calves that were being weaned at a fixed age. In the present study of calves being weaned according to their starter intake, we found slightly different correlations: visits to the milk feeder were negatively correlated with milk intake but were not negatively correlated with total energy intake; in fact, when we examined the whole period from d 20 to 87 , the frequency of visits was positively correlated with energy intake. This suggests that frequent visits to the milk feeder are specifically a result of lowered milk intake rather than low energy intake. When calves are weaned at a fixed age, especially when young and over a short period of time, they cannot increase starter intake rapidly enough to compensate for the reduced milk intake. Consequently, a strong correlation exists between milk intake and energy intake and WG (de Passillé et al., 2011). However, in the present study, the fact that milk allowance was reduced only when calves were eating a certain amount of starter reduced the link between milk intake and overall energy intake. Although the frequency of visits to the milk feeder did increase at weaning, the daily frequency of visits that we noticed $(10-15 / \mathrm{d})$ were substantially lower than those reported either for calves on low milk allowance or calves being weaned at 6 to 8 wk of age $(20-25 /$ d; Borderas et al., 2009; de Passillé et al., 2011), and more resemble the frequencies of calves being weaned at 12 to 13 wk of age (10-12/d; de Passillé et al., 2011).

Concern often exists that allowing calves to eat hay may reduce their intakes of starter (Drackley, 2008) but 
more recent evidence does not support this (de Passillé et al., 2011; Khan et al., 2011b; Castells et al., 2012), although the type of forage may be important (Castells et al., 2012). The present results also provide some indirect evidence against this point of view. At no time was starter intake negatively correlated with hay intake; in fact, when we examined the whole period from d 20 to 87, the correlation was positive, showing that calves that were eating more hay were also eating more starter. Hay intake was negatively correlated with milk intake but the correlations were smaller than between milk intake and starter intake, which supports our previous findings (de Passillé et al., 2011) that hay does not substitute for milk as readily as does starter.

Previously, Roth et al. (2009) reported that weaning according to starter intake did result in earlier weaning but did not improve WG during weaning. We did not compare the effects of weaning according to starter intake with weaning at a fixed age, but in this study we found good WG (averaging more than $1 \mathrm{~kg} / \mathrm{d}$ ) during the process of weaning, whereas WG usually decrease when calves are weaned at a fixed age (de Passillé et al., 2011). In this study, only $1 / 60$ calves $(<2 \%)$ lost weight during weaning, whereas we found that almost $10 \%$ of calves weaned at a fixed age lost weight during weaning (de Passillé et al., 2011). Similar to Roth et al. (2009), by adjusting weaning age according to each calf's ability to eat solid feed, we were able to reduce the age at weaning while maintaining good WG over the weaning period. However, continued research would help identify the optimum parameters for weaning.

\section{CONCLUSIONS}

Adjusting the age at which individual calves are weaned off milk according to their ability to eat solid feed can reduce the age at which weaning occurs while reducing the negative effects of weaning on energy intake and WG, although the increased visits to the milk feeder during weaning suggest that calves may remain motivated to drink milk. This method of weaning allows us to profit from some calves' ability to eat solid food at an early age, while avoiding the problems that arise from other calves' difficulties to do so. The targets used to start and end weaning did not have strong overall effects on the calves, except that one disadvantage with having too high a target to start weaning is that smaller calves will be weaned at a late age, whereas too low a target to end weaning results in some very short weaning periods.

\section{ACKNOWLEDGMENTS}

We thank J. P. Parent, G. Zdanowicz, and the numerous students (Agriculture and Agri-Food Canada, Agassiz, BC, Canada), and M. A. Khan, N. Dinn, and the dairy staff (University of British Columbia, Agassiz, BC, Canada) for invaluable help. Funding was provided by Agriculture and Agri-Food Canada and the Natural Sciences and Engineering Research Council of Canada (both in Ottawa, ON, Canada).

\section{REFERENCES}

Borderas, T. F., A. M. B. de Passillé, and J. Rushen. 2009. Feeding behavior of calves fed small or large amounts of milk. J. Dairy Sci. 92:2843-2852.

Castells, L., A. Bach, G. Araujo, C. Montoro, and M. Terré. 2012. Effect of different forage sources on performance and feeding behavior of Holstein calves. J. Dairy Sci. 95:286-293.

de Passillé, A. M., T. F. Borderas, and J. Rushen. 2011. Weaning age of calves fed a high milk allowance by automated feeders: Effects on feed, water, and energy intake, behavioral signs of hunger, and weight gains. J. Dairy Sci. 94:1401-1408.

De Paula Vieira, A., V. Guesdon, A. M. de Passillé, M. A. G. von Keyserlingk, and D. M. Weary. 2008. Behavioural indicators of hunger in dairy calves. Appl. Anim. Behav. Sci. 109:180-189.

Drackley, J. K. 2008. Calf nutrition from birth to breeding. Vet. Clin. North Am. Food Anim. Pract. 24:55-86.

Jasper, J., and D. M. Weary. 2002. Effects of ad libitum milk intake on dairy calves. J. Dairy Sci. 85:3054-3058.

Jensen, M. B. 2006. Computer-controlled milk feeding of group-housed calves: The effect of milk allowance and weaning type. J. Dairy Sci. 89:201-206.

Khan, M. A., D. M. Weary, and M. A. G. von Keyserlingk. 2011a. Invited review: Effects of milk ration on solid feed intake, weaning, and performance in dairy heifers. J. Dairy Sci. 94:1071-1081.

Khan, M. A., D. M. Weary, and M. A. G. Von Keyserlingk. 2011b. Hay intake improves performance and rumen development of calves fed higher quantities of milk. J. Dairy Sci. 94:3547-3553.

Nielsen, P. P., M. B. Jensen, and L. Lidfors. 2008. Milk allowance and weaning method affect the use of a computer controlled milk feeder and the development of cross-sucking in dairy calves. Appl. Anim. Behav. Sci. 109:223-237.

NRC. 2001. Nutrient Requirements of Dairy Cattle. 7th rev. ed. NRC, Washington, DC

Roth, B. A., N. M. Keil, L. Gygax, and E. Hillmann. 2009. Influence of weaning method on health status and rumen development in dairy calves. J. Dairy Sci. 92:645-656.

Soberon, F., E. Raffrenato, R. W. Everett, and M. E. Van Amburgh. 2012. Preweaning milk replacer intake and effects on long-term productivity of dairy calves. J. Dairy Sci. 95:783-793.

Sweeney, B. C., J. Rushen, D. M. Weary, and A. M. de Passillé. 2010. Duration of weaning, starter intake, and weight gain of dairy calves fed large amounts of milk. J. Dairy Sci. 93:148-152. 